\title{
CARRIAGE FREQUENCY, PHENOTYPIC AND GENOTYPIC CHARACTERISTICS OF Staphylococcus aureus ISOLATED FROM DIALYSIS AND KIDNEY TRANPLANT PATIENTS AT A HOSPTIAL IN NORTHERN PARANÁ
}

\author{
Luciana Borges Giarola ${ }^{1 *}$, Rosiane Ribeiro dos Santos ${ }^{1}$, Maria Cristina Bronharo Tognim², Sueli Donizete Borelli ${ }^{3}$, João \\ Bedendo $^{4}$
}

${ }^{1}$ Universidade Estadual de Maringá, Enfermagem, Maringá, PR, Brasil; ${ }^{2}$ Departamento de Microbiologia, Universidade Estadual de Maringá, Maringá, PR, Brasil; ${ }^{3}$ Departamento de Imunologia, Universidade Estadual de Maringá, Maringá, PR, Brasil; ${ }^{4}$ Departamento de Enfermagem, Universidade Estadual de Maringá, Maringá, PR, Brasil.

Submitted: March 16, 2011; June 07, 2012.

\begin{abstract}
The objective of the present study was to determine the frequency of Staphylococcus aureus nasal carriage among dialysis and kidney transplant patients, to identify the antimicrobial resistance profile of these strains and to verify their genetic profiles with the RW3A primer. The study included 159 individuals, comprising 111 dialysis and 48 kidney transplant patients. Of the 48 transplant patients, $75 \%$ were positive for $S$. aureus, whereas $49 \%$ of the 111 dialysis patients were carriers. Two samples yielded conflicting results for oxacillin sensitivity between the disk diffusion and minimum inhibitory concentration (MIC) assays: both were sensitive by the disk diffusion assay and resistant by MIC $(4 \mu \mathrm{g} / \mathrm{ml})$. In the antibiogram by disk diffusion, ten samples were resistant to cefoxitin, among which eight were also resistant to oxacillin. The resistance of the ten samples to cefoxitin by the disk diffusion assay was confirmed by MIC. Of the ten oxacillin-resistant samples, eight harbored the mecA gene. All samples were sensitive to vancomycin, and most were resistant to penicillin and demonstrated high rates of resistance to the other antimicrobials tested. The samples from dialysis patients exhibited a more homogenous genetic profile. Among the samples with a high percent similarity, no correlation with sensitivity or resistance to oxacillin was observed. According to the results of this study, the implementation of prevention and control measures, such as increased restrictions on prescriptions for antimicrobial drugs and nasal decontamination prior to high-risk procedures, is recommended.
\end{abstract}

Key words: Staphylococcus aureus, nasal carrier, resistance, mecA gene, genetic typing.

\section{INTRODUCTION}

Nasal colonization by Staphylococcus spp. begins soon after birth, increases during infancy and decreases in adulthood
(9). Colonized individuals can develop endogenous infections with strains that disseminate from the nasopharynx, which constitute $80 \%$ of cases of invasive Staphylococcus aureus infection. Approximately $20 \%$ of adults are carriers of $S$.

\footnotetext{
*Corresponding Author. Mailing address: Rua Osvaldo Cruz, 317, apto 201, Zona 07, Maringá, Paraná, Brasil.; Tel.: 44-3034-8658.; E-mail: $\underline{\text { lu giarola@hotmail.com }}$
} 
aureus in the nasopharynx, 30\% are intermittent carriers, and $50 \%$ are non-carriers $(15,45)$.

Staphylococcus aureus and coagulase-negative Staphylococcus spp. are among the most prevalent pathogens of dialysis and kidney transplant patients $(1,17)$. These individuals possess risk factors for colonization and infection with multidrug-resistant $S$. aureus because of their frequent and prolonged use of antimicrobials. Moreover, these patients undergo frequent admission to the hospital and invasive procedures and maintain contact with colonized patients and professionals. Kidney transplant recipients are at additional risk due to the use of immunosuppressive therapies, which are initiated soon after transplant $(19,36)$.

S. aureus is highly versatile in acquiring antimicrobial resistance, especially to beta-lactam drugs such as oxacillin (4, 26). Beta-lactam resistance is encoded by the mecA gene, which is located on the staphylococcal cassette chromosome mec (SCCmec). SCCmec confers resistance to oxacillin and is transferable between species of Staphylococcus (12). In addition to the mec $A$ gene, other resistance mechanisms can be involved, such as enzymatic degradation of antimicrobials, alterations in membrane permeability and active site alteration (5).

Polymerase chain reaction (PCR) using specific primers (40) is one of several molecular techniques utilized for bacterial studies. It is possible to detect antimicrobial resistance genes, differentiate samples with identical phenotypes, establish dissemination routes, relate isolates from different sources and compare the genotypes of samples dispersed in the environment using PCR (23).

PCR amplification of repetitive sequences (REP-PCR) can be used to better understand the evolutionary relationships between $S$. aureus clones that are resistant to oxacillin (ORSA) (10) and to trace and identify the transmission source. The RW3A primer is a repetitive sequence that permits the genetic distinction of phenotypically equivalent strains of $S$. aureus (35).
Considering the importance of nasal carriage of $S$. aureus in the epidemiology of staphylococcal infection and that a significant percentage of these infections are of endogenous origin (29), the following objectives were proposed for this study: to investigate the frequency of nasal carriage of $S$. aureus among dialysis and kidney transplant patients, to identify the resistance profiles of these isolates for commonly used antimicrobial therapies; to verify the presence of the mec $A$ gene in oxacillin-resistant samples and to identify the genetic profile of the samples and correlate the findings.

\section{MATERIALS AND METHODS}

\section{Study site and population}

This correlational, exploratory and descriptive study included patients who were treated at the Santa Casa de Maringá hospital dialysis center, including those undergoing dialysis and those who received a kidney transplant. The study population was composed of 159 individuals, including 111 dialysis patients and 48 kidney transplant recipients. Of the dialysis patients, 54,1\% (60/111) were male and 45.9\% $(51 / 111)$ were female, and age varied between 15 and 93 years old. Among the kidney transplant patients, 64.5\% (31/48) were male and $35.4 \%$ (17/48) were female, and age varied between 18 and 64 years old. One sample per patient was collected during the period from June to November 2009.

\section{Laboratory procedures}

\section{Collection, identification and storage of biological}

material: Samples from the nares were obtained with sterile swabs that were subsequently placed into tubes containing Trypticase Soy Broth (TSB) with 6.5\% NaCl, incubated for 24 hours in an incubator and plated on Petri dishes containing mannitol salt agar (MSA) (Becton, Dickinson and Company, BD Diagnostic Systems, USA) (13). After incubation at $37^{\circ} \mathrm{C}$ for 24-48 hours, Gram staining (41) was performed on suspected $S$. aureus colonies, and those identified as clustered 
Gram-positive cocci were subjected to the coagulase test (22). After identification, samples were stored in TSB medium containing $20 \%$ glycerol at $-20^{\circ} \mathrm{C}$.

\section{Antimicrobial sensitivity}

Disk diffusion assay: Disk diffusion assays were performed according to the standards recommended in document M2-A10 from the Clinical and Laboratory Standards Institute (CLSI) (5) with the following antimicrobials: $1 \mu \mathrm{g}$ oxacillin, $30 \mu \mathrm{g}$ cefoxitin, $10 \mu \mathrm{g}$ gentamicin, $30 \mu \mathrm{g}$ tetracycline, $10 \mu \mathrm{g}$ penicillin $\mathrm{G}, 15 \mu \mathrm{g}$ azithromycin, $\quad 2 \mu \mathrm{g} \quad$ clindamycin, $75 \quad \mu \mathrm{g}$ trimethoprim/sulfamethoxazole, $30 \mu \mathrm{g}$ doxycycline, $5 \mu \mathrm{g}$ rifampin, $30 \mu \mathrm{g}$ teicoplanin or $5 \mu \mathrm{g}$ ofloxacin. $S$. aureus control samples were obtained from the American Type Culture Collection (ATCC). One sample was sensitive (ATCC 25923) and one was resistant to oxacillin (ATCC 43300). Halo diameters were compared with those described in Table 1, document M100-S20 of the Clinical and Laboratory Standards Institute (6). Results that were interpreted as intermediate were considered to be resistant.

\section{Determination of Minimum Inhibitory Concentration}

(MIC): MIC was determined for oxacillin and vancomycin by the agar dilution method following the methodology proposed in document M7-A8 from the Clinical and Laboratory Standards Institute (7). ATCC samples 29213 and 43300 were used as positive controls. Readings of results were performed according to standards described in Table 1 of document M100-S20 from the Clinical and Laboratory Standards Institute (6).

\section{Polymerase Chain Reaction}

DNA Extraction: For PCR with various primers, DNA was extracted from $S$. aureus samples with cetyltrimethylammonium bromide (CTAB) (14).

Identification of the mec $A$ gene and genotyping: The $m e c A$ gene was identified in oxacillin-resistant samples with primers MRS1- 5' TAGAAATGACTGAACGTCCG 3' and
MRS2- 5' TTGCGATCAATGTTACCGTAG 3' $(38,43)$. The amplified products were visualized with gel electrophoresis on a 1.5\% agarose gel stained with ethidium bromide. A 154-base pair (bp) amplicon indicated the presence of the mecA gene.

Genetic typing of the samples was performed with PCR using the RW3A primer (5'- TCGCTCAAAACAACGACACC 3') (44). The amplified product was analyzed after separation on a $1.5 \%$ agarose gel stained with ethidium bromide. Analysis of the standards was performed visually, and the degree of similarity between the samples was obtained using NT SYS, and the results are presented in a dendrogram.

\section{Ethical Considerations}

This study observed and respected all of the rules contained in the 196/96 Resolution of the National Council of Health and was approved by the Permanent Committee for Ethics in Research Involving Human Subjects (Comitê Permanente de Ética em Pesquisa Envolvendo Seres Humanos - COPEP) of the UEM, under registration number 212/2009 (3).

\section{RESULTS AND DISCUSSION}

Among the 48 kidney transplant recipients, 36 (75\%) were positive for S. aureus in their nares, whereas 55 (49\%) of the 111 dialysis patients were carriers. These high rates of nasal colonization are comparable with other reports that show similar rates (33). Palos (34) found a $S$. aureus carriage rate of $84.7 \%$ among health care professionals. In the general population, an average rate of $37.2 \%$ was observed by Kluytmans et al. (23), who found higher carriage frequencies among patients who were repeatedly subjected to skin puncture, such as patients receiving hemodialysis or continuous ambulatory peritoneal dialysis. Because the carriage of this bacterium appears to be a predictor of infection, its identification has become a necessary prevention strategy (18).

Ten samples were resistant to cefoxitin, among which eight were also resistant to oxacillin on a disk diffusion 
antibiogram. The CLSI (6) recommends combining oxacillin and cefoxitin resistance results so that readings are more precise and reliable. The identification of oxacillin resistance is epidemiologically important because this drug is a marker of resistance to other groups of beta-lactam antibiotics that target the bacterial cell wall. Changes in penicillin binding proteins (PBPs) diminish their affinity for the antimicrobial (28). Nosocomial and community-associated penicillinase-producing staphylococci may also be resistant to other classes of antimicrobials, such as macrolides, aminoglycosides, streptomycin and tetracycline (24).

The observed resistance rate for oxacillin (11\%) and the total sensitivity to vancomycin correspond to the results obtained by Faria (16). The complete sensitivity to vancomycin among the samples observed in this study was expected because in Brazil, few studies have reported the isolation of samples resistant to this drug $(24,30,32)$. Studies have warned of the need for policies to prevent the inappropriate or unnecessary use of the glycopeptides vancomycin and teicoplanin and to reduce the opportunity for the emergence and spread of resistant or insensitive strains (8).

We observed $100 \%$ sensitivity to teicoplanin and approximately $90 \%$ resistance to penicillin, $14 \%$ to rifampin and $59 \%$ to azithromycin. High rates of resistance to penicillin among $S$. aureus strains have been observed since 1959, when this frequency was $80 \%$, which has since extended to amoxicillin and to ampicillin (27). The prevalence of resistance to rifampicin (14\%) and gentamicin (19\%) and the complete sensitivity to teicoplanin observed in this study are similar to results obtained by Menegoto and Picoli (31). Table 1 lists the results of antimicrobial susceptibility testing by the disk diffusion assay for $S$. aureus samples isolated from dialysis and kidney transplant patients from the Santa Casa de Maringá hospital in 2009.

Table 1. Distribution of antimicrobial resistance by disk diffusion to $S$. aureus isolated from dialysis and kidney transplant patients at Santa Casa hospital of Maringá, 2009.

\begin{tabular}{cccc}
\hline Antimicrobianos & Transplantados Renais & Diálise & Total \\
\cline { 2 - 3 } Penicilina & $(34 / 36) 94 \%$ & $(50 / 55) 90 \%$ & $(84 / 91) 92 \%$ \\
Cefoxitina & $(06 / 36) 16 \%$ & $(04 / 55) 3,6 \%$ & $(10 / 91) 11 \%$ \\
Oxacilina & $(06 / 36) 16 \%$ & $(02 / 55) 7,2 \%$ & $(8 / 91) 8,7 \%$ \\
Azitromicina & $(24 / 36) 66 \%$ & $(30 / 55) 54 \%$ & $(54 / 91) 59 \%$ \\
Clindamicina & $(24 / 36) 66 \%$ & $(21 / 55) 38 \%$ & $(45 / 91) 49 \%$ \\
Trimetropin/sulfametoxazol & $(19 / 36) 52 \%$ & $(16 / 55) 29 \%$ & $(35 / 91) 38 \%$ \\
Tetraciclina & $(26 / 36) 72 \%$ & $(20 / 55) 36 \%$ & $(46 / 91) 50 \%$ \\
Doxicilina & $(09 / 36) 25 \%$ & $(13 / 55) 23 \%$ & $(22 / 91) 24 \%$ \\
Rifampicina & $(07 / 36) 19 \%$ & $(06 / 55) 10 \%$ & $(13 / 91) 14 \%$ \\
Gentamicina & $(09 / 36) 25 \%$ & $(09 / 55) 16 \%$ & $(18 / 91) 19 \%$ \\
Teicoplamina & $(00 / 36) 0 \%$ & $(00 / 55) 0 \%$ & $(0 / 91) 0 \%$ \\
Ciprofloxacina & $(24 / 36) 66 \%$ & $(16 / 55) 29 \%$ & $(40 / 91) 43 \%$ \\
\hline
\end{tabular}

MIC determination was utilized to confirm the oxacillin resistance profile observed by disk diffusion and to test for vancomycin resistance. The ten samples that were resistant to cefoxitin by disk diffusion were confirmed by MIC, which varied between $4 \mu \mathrm{g} / \mathrm{ml}$ and $256 \mu \mathrm{g} / \mathrm{ml}$. Approximately $30 \%$ $(3 / 10)$ of the samples demonstrated a MIC of $4 \mu \mathrm{g} / \mathrm{ml}, 10 \%$ $(1 / 10)$ exhibited a MIC of $8 \mu \mathrm{g} / \mathrm{ml}, 20 \%(2 / 10)$ showed a MIC of $16 \mu \mathrm{g} / \mathrm{ml}$, and $40 \%(4 / 10)$ demonstrated a MIC of 256 $\mu \mathrm{g} / \mathrm{ml}$. For two samples, the results of the disk diffusion assay differed from those of the MIC test for oxacillin resistance. Both samples exhibited sensitivity by disk diffusion and resistance by MIC, with values equal to the $4-\mu \mathrm{g} / \mathrm{ml}$ threshold. These results support the proposal of the CLSI (5), which advocates for the confirmation of results from the disk 
diffusion assay with those of the MIC test using standard strains (ATCC) that are known to be sensitive and resistant.

The results of antimicrobial susceptibility testing demonstrated that of the ten samples resistant to oxacillin by MIC, six (60\%) exhibited a MIC of $2 \mu \mathrm{g} / \mathrm{ml}$ and four (40\%) demonstrated a MIC of $1 \mu \mathrm{g} / \mathrm{ml}$ for vancomycin, with all defined as vancomycin-sensitive. Combining the results of sensitivity testing (MIC) for oxacillin and vancomycin did not reveal an association, independent of the observed values, because all of the samples were sensitive to vancomycin.

$S$. aureus antimicrobial resistance may be chromosomally encoded or mediated by plasmids. With respect to oxacillin resistance, the hyperproduction of beta-lactamases, changes in the binding capacity of PBPs or the presence of an altered PBP known as PBP2a may be observed (42). This altered PBP is encoded by a chromosomal gene known as mecA, which is responsible for the intrinsic resistance of staphylococci to oxacillin and all of the beta-lactam antibiotics (11).

The presence of the mecA gene was identified in eight of the ten samples $(80 \%)$ that were resistant to oxacillin by MIC.
A previous study by Faria (16) reported similar percentages in samples from the community. More recent studies have demonstrated the efficacy of the disk diffusion assay for cefoxitin as a substitute marker for the detection of oxacillin resistance by the mecA gene $(2,39)$.

The degree of similarity between 48 of the 55 samples isolated from the group of dialysis patients was evaluated using PCR with the RW3A primer. No amplification product was obtained from seven of the samples. Among the 48 typed samples, 27 had a degree of similarity greater than $80 \%$, and the remaining isolates (21) exhibited a degree of similarity that varied between $20 \%$ and $80 \%$.

Comparisons among 16 of the 48 samples revealed eight genotypes, and distinct profiles were observed for the remaining samples. This result signifies the presence of strains with identical genotypes; however, no one single genotype was dispersed throughout the dialysis unit of this institution. The results of the genetic similarity analysis with the RW3A primer of the S. aureus samples isolated from dialysis patients are presented in Figure 1.

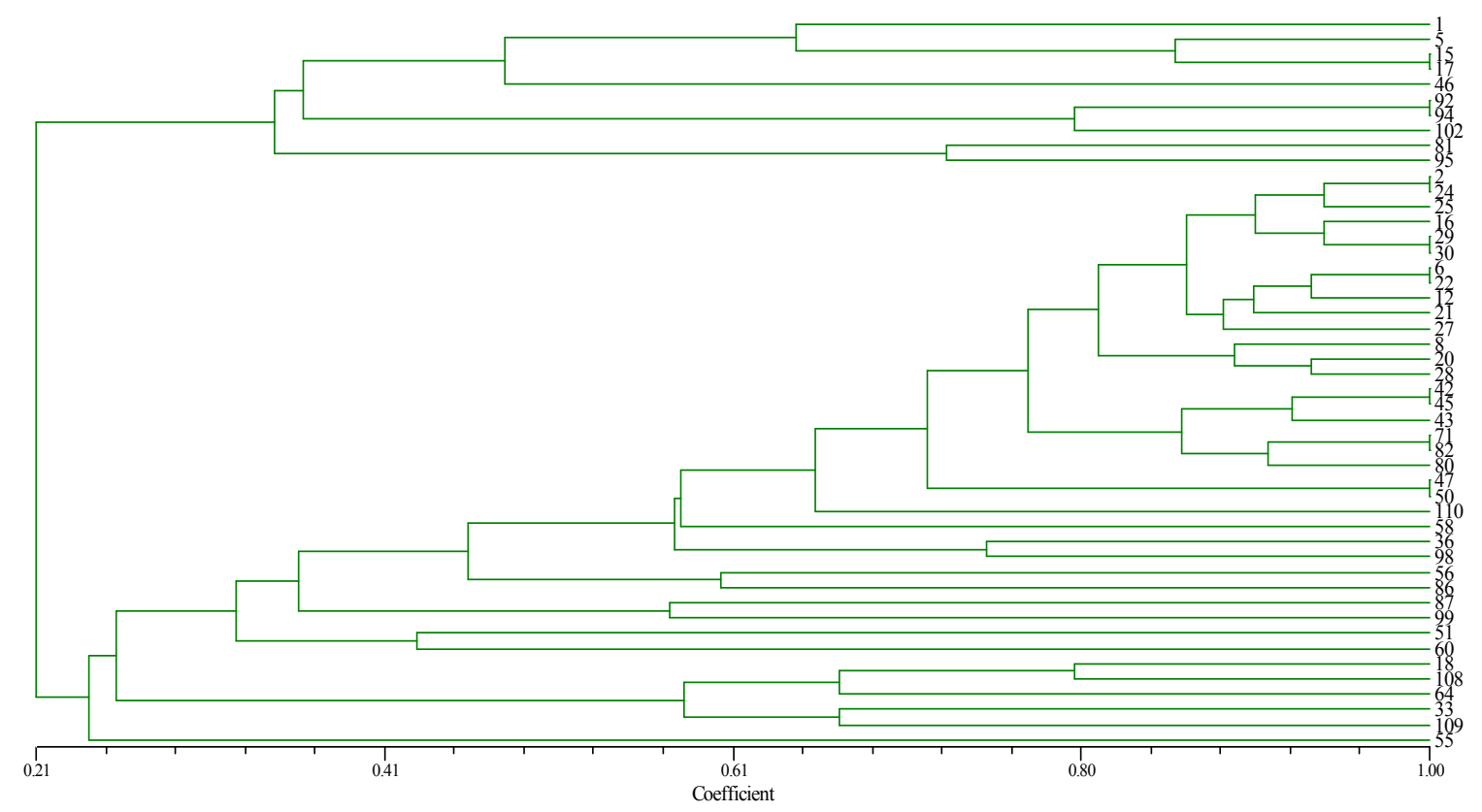

Figure 1. Analysis of similarity results for S. aureus samples isolated from dialysis patients, using Numerical Taxonomy System software (NTSYS). 
The results of genetic similarity testing revealed that of the $36 S$. aureus samples isolated from kidney transplant patients, two exhibited 95\% similarity, eight demonstrated approximately $90 \%$ similarity, and the remaining samples (28) showed less than $80 \%$ similarity. Similar to the dialysis group, a single genotype that was disseminated throughout the institution was not identified among kidney transplant recipients, as $100 \%$ similarity was not observed. The results of genotyping with the RW3A primer for the analysis of genetic similarity among the $S$. aureus samples isolated from transplant patients are presented in Figure 2.

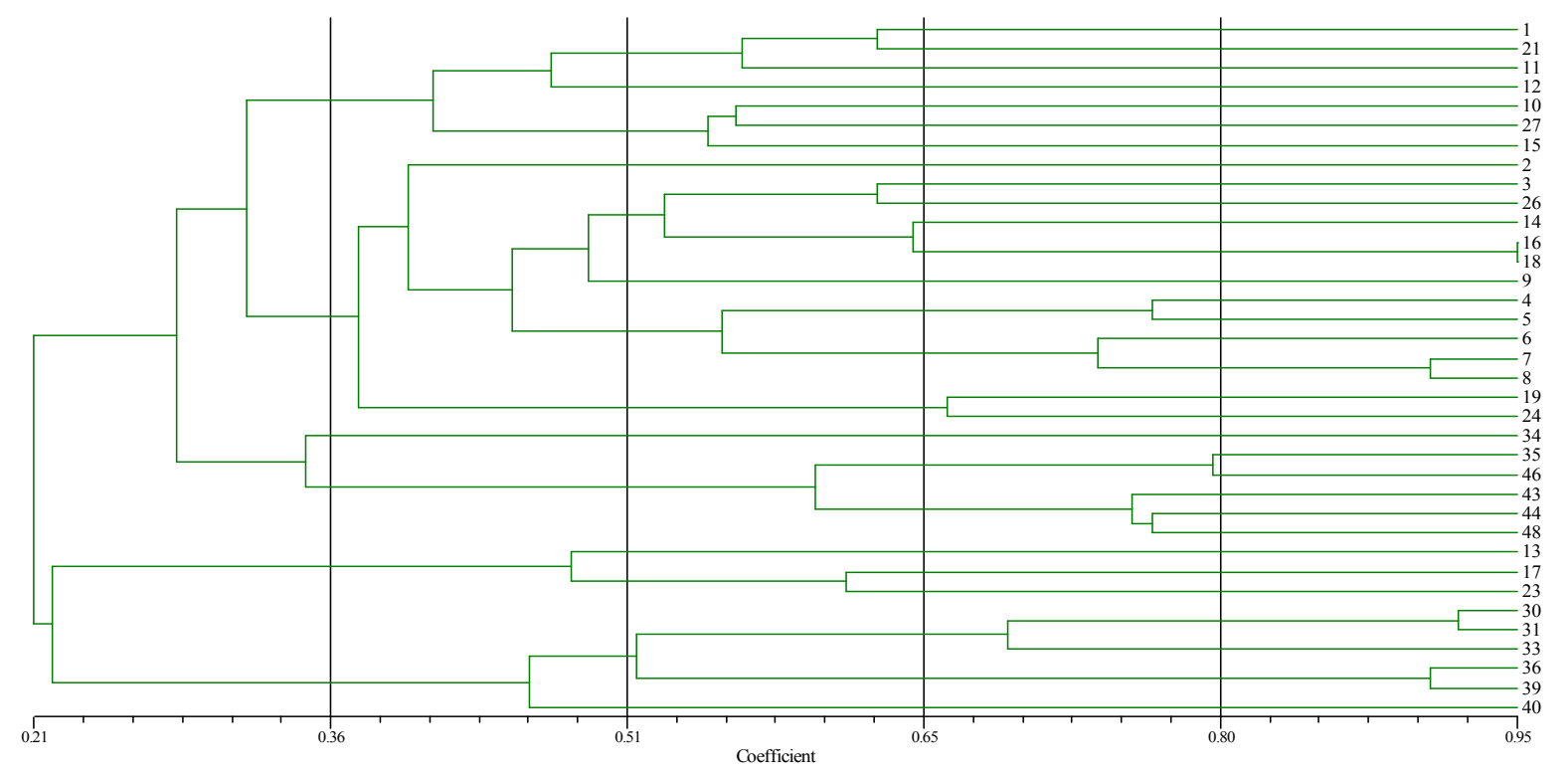

Figure 2. Analysis of similarity results for S. aureus samples isolated from kidney transplant patients, using Numerical Taxonomy System software (NTSYS).

With genetic typing, a more homogenous profile was observed among the samples isolated from dialysis patients than among those isolated from kidney transplant patients. Few studies have reported using the RW3A primer for typing $S$. aureus samples isolated from humans. A study performed by Santos and Darini (37) identified little similarity among $S$. aureus isolates from children and employees of a hospital; however, the authors emphasized the important role of genotyping in the research design because the antibiogram alone did not provide sufficient criteria for sample distinction (37).

Among the sixteen $S$. aureus samples isolated from dialysis patients, eight genotypes that grouped in pairs were identified. In seven of these eight genotypes, fourteen samples were sensitive to oxacillin, and in one genotype, two isolates exhibited different profiles, with one oxacillin-sensitive and one oxacillin-resistant sample. Among the samples isolated from transplant patients, only two exhibited 95\% similarity, and both were sensitive to oxacillin. Establishing a correlation between antimicrobial resistance and dissemination of clonal $S$. aureus groups is an important tool during outbreaks or in endemic settings. Jones et al. (20) demonstrated using PCR with the RW3A primer the existence of clones among mupirocin-resistant samples of MRSA from the nares of patients admitted to the Surgical Intensive Care Unit. In our study, no correlation was observed between genetic similarity and oxacillin sensitivity and resistance.

Considering the high rate of $S$. aureus carriage and the 
multidrug resistance profile of the samples demonstrated in this study, we recommend the implementation of prevention and control measures, including decontamination of nasal carriers, restricted use of the antimicrobials commonly used in clinical practice to which resistance is most frequent, active search for carriers among contacts, tracking of dissemination sources and a detailed study of antimicrobial resistance with reliable methodologies. Moreover, the susceptibility to mupirocin needs to be determined with greater methodological rigor, and its use in the nasal decontamination of carriers of multidrugresistant strains should be evaluated.

\section{REFERENCES}

1. Alonso-Morquecho, A.; Flores-Preciado, H.; Martínez-García, M.C. (2000). Prevalence of infection in patients with central venous catheters. Revista Enf. IMSS. 8 (3), 139-143.

2. Anand, K.B.; Agrawal, P.; Kumar, S.; Kapila, K. (2009). Comparison of cefoxitin disc diffusion test, oxacillin Screen Agar, and PCR for mecA gene for detection of MRSA. Indian J Med Microbiol. 27 (1), 27-29.

3. Brasil. Ministério da Saúde. Conselho Nacional de Saúde. Resolução ${ }^{\circ}$ 196/96 - Diretrizes e normas regulamentadoras de pesquisas envolvendo seres humanos. Brasília, DF: MS/FIOCRUZ, 1996.

4. Brasil. Detecção e identificação de bactérias de importância médica. Brasília, DF, 2004a.

5. Clinical and Laboratory Standards Institute. Performance Standards for antimicrobial disk susceptibility tests: approved standard. CLSI. 10. ed. M02-A10. Wayne, PA, 2009a.

6. Clinical and Laboratory Standards Institute. Performance Standards for antimicrobial susceptibility testing: nineteenth informational supplement. CLSI. Document M100-S20. Wayne, PA, 2010b.

7. Clinical and Laboratory Standards Institute. Methods for dilution antimicrobial susceptibility tests for bacteria that grow aerobically: approved standard. CLSI. 8. ed. Document M07-A8. Wayne, PA, 2009c.

8. Coia, J.; Duckworth, G.; Edwards, D.; Farrington, M.; Fry, C.; Humphreys, H.; Mallaghan, C.; Tucker, D. (2006). Guidelines for the control and prevention of methicillin-resistant Staphylococcus aureus (MRSA) in healthcare facilities. J. Hosp. Infect. 63, 1-44.

9. Datta, F.; Erb, T.; Heininger, U.; Gervaix, A.; Schaad, U.B.; Berger, C.; Vaudaux, B.; Aebi, C.; Hitzler, M.; Kind, C.; Gnehm, H.E.; Frei, R. (2008). A multicenter, cross-sectional study on the prevalence and risk factors for nasal colonization with Staphylococcus aureus in patients admitted to children's hospitals in Switzerland. Clin Infect Dis. 47 (7), 923-926.
10. De Lencastre, H.; Wu, S.W.; Pinho, M.G.; Ludovice, A.M.; Filipe, S.; Gardete, S.; et al. (1999). Antibiotic resistance as a stress response: complete sequencing of a large number of chromosomal loci in Staphylococcus aureus strain COL that impact on the expression of resistance to methicillin. Microbial Drug Resistance. 5 (3), 163-175.

11. De Lencastre, H.; Oliveira, D.; Tomasz, A. (2007). Antibiotic resistant Staphylococcus aureus: a paradigm of adaptive power. Current Opinion in Microbiology. 10 (5), 428-435.

12. Deurenberg, R.H.; Stobberingh, E.E. (2008). The evolution of Staphylococcus aureus. Infection, Genetics and Evolution. J. Clin. Microbiol. 8 (6), 747-763.

13. Dias Filho BP, Abreu Filho BA, Cardoso CL, Nakamura CV, Garcia LB, Guilhermetti M, Tognin MCB, Nakamura TU. Manual de aulas práticas: Enfermagem. Maringá: Universidade Estadual de Maringá. Departamento de Análises Clínicas, 2001.

14. Doyle, J.J.; Doyle, J.L. (1990). Isolation of plant DNA from fresh tissue. Focus. 12 (1), 13-15.

15. Fabiano, T.L.T.; Ávila, B.H.P.; Dias, C.C.; Maluta, R.P.; Ávila, F.A. (2008). Genetic similarity between Staphylococcus $s \mathrm{p}$ isolated from human and hospital settings, and susceptibility to different antimicrobials. Braz. J. Microbiol. 39 (4), 652-657.

16. Faria, S.T. (2009). Staphylococcus aureus entre estudantes de enfermagem saudáveis. Maringá, Paraná, Brasil, 57p. (M.Sc. Dissertation. Programa de Pós-graduação em Enfermagem, Universidade Estadual de Maringá. UEM).

17. Ferreira, V.; Andrade, D.; Santos, C.B.; Neto, M.M. (2005). Infection in patient with temporary double-lumen catheter for hemodialysis. Rev Panam Infectol. 7 (2), 16-21.

18. Gold, I.M. (2005). The clinical significance of methicillin-resistant Staphylococcus aureus. Journal of Hospital Infection. 61 (4), 277-282.

19. Hong, F.; Goran, H. (2006). Use of cefoxitin-based selective broth for improved detection of methicillin-resistant Staphylococcus aureus. J. Clin. Microbiol. 44 (2), 592-594.

20. Jones, J.C.; Rogers, T.J.; Brookmeyer, P.; Dunne Junior, W.M.; Storch, G.A.; Coopersmith, C.M.; et al. (2007). Mupirocin Resistance in Patients Colonized with Methicillin-Resistant Staphylococcus aureus in a Surgical Intensive Care Unit. Clinical Infectious Diseases. 45, 541-547.

21. Kluytmans, J.; Van Belkum, A.; Verbrugh, H. (1997). Nasal carriage of Staphylococcus aureus: epidemiology, underlying, mechanisms, and associated risks. Clin Microbiol Rev. 10 (3), 505-520.

22. Koneman, E.W. et al. (2008). Diagnóstico Microbiológico: texto e atlas colorido. 6. ed. Rio de Janeiro: Medsi.

23. Liao, R.S.; Storch, G.A.; Buller, R.S.; Orscheln, R.C.; Mardis, E.R.; Armstrong, J.R.; et al. (2006). Blinded Comparison of RepetitiveSequence PCR and Multilocus Sequence Typing for Genotyping Methicillin-Resistant Staphylococcus aureus Isolates from a Children's Hospital in St. Louis, Missouri. J. Clin. Microbiol. 44(6), 2254-2257. 
24. Lowy, F.D. (2003). Antimicrobial resistance: the example of Staphylococcus aureus. J. Clin. Invest. 111(9), 1265-1273.

25. Lutz, L.; Machado, A.; Kuplich, N.; Barth, A.L. (2003). Clinical failure of vancomycin treatment of Staphylococcus aureus infection in a tertiary care hospital in southern Brazil. Braz J Infect Dis. 7 (3), 224-228.

26. Lutz, L.; Barth, A.L. (2006). Susceptibility of Staphylococcus aureus isolates to vancomycin at a university hospital in southern Brazil. Braz. J. Microbiol. 37, 244-246.

27. Mamizuka, E. (2005). Projeto de resistência microbiana em serviços de saúde, Staphylococcus. Agência Nacional de Vigilância Sanitária, ANVISA. http//:www.anvisa.gov.br

28. Mandell, G.L.; Bennett, J.E.; Dolin, R. (2005). Mandell, Douglas, and Bennett's Principles and Practice of Infectious Diseases. 6. ed. Philadelphia: Elsevier Churchill Livingstone, 2005.

29. Martins Júnior, P.O.; Porto, E.R.; Silva, R.N.; Pinhati, H.M.S. (2009). Prevalence of meticilin resistent Staphylococcus aureus isolated in blood cultures of hospitalized patients in Some Hospitals at Distrito FederalBrazil. Brasília Med. 46 (2), 125-130.

30. Melo, G.B.; Melo, M.C.; Gama, A.P.; Carvalho, K.S.; Jesus, T.C.; Bonetti, A.M.; Gontijo Filho, P.P. (2005). Analysis of the genetic diversity of vancomycin-resistant Staphylococcus aureus. Braz. J. Microbiol. 36 (2), 126-130.

31. Menegotto, F.R.; Picoli, S.V. (2007). Staphylococcus aureus oxacilina resistente (MRSA): incidência de cepas adquiridas na comunidade (CAMRSA) e importância da pesquisa e descolonização em hospital. Rev. Bras. Anal. Clin. 39 (2), 147-150.

32. Oliveira G.A.; Dell'Aquila, A.M.; Masiero, R.L.; Levy, C.E.; Gomes, M.S.; Cui, L.; Hiramatsu, K.; Mamizuka, E.M. (2001). Isolation in Brazil of nosocomial Staphylococcus aureus with reduced susceptibility to vancomycin. Infect Control Hosp Epidemiol. 22(7): 443-448.

33. Padoveze, M.C. (2004). Estudo das infecções hospitalares em pacientes com HIV/AIDS hospitalizados e da colonização nasal pos Staphylococcus aureus em pacientes com HIV/AID não hospitalizados. Campinas, São Paulo, Brasil, 135p. (Tese de doutorado. Programa de Pós-graduação em Clínica Médica, Faculdade de Ciências Médicas, Universidade Estadual de Campinas, Campinas).

34. Palos, M.A.P. (2006). Staphylococcus aureus e Staphylococcus aureus meticilina resistentes (MRSA) em profissionais de saúde e as interfaces com as infecções nosocomiais. São Paulo, Brasil, 184p. (Tese de doutorado. Escola de Enfermagem de Ribeirão Preto, Universidade de São Paulo, Ribeirão Preto).
35. Reinoso, E.; Bettera, S.; Odierno, L.; Bogni, C.; et al. (2007). Rep-PCR of Staphylococcus aureus strains isolated from bovine mastitis in Argentina. Braz. J. Vet. Res. Anim. Sci. 4: 115-121. Suplemento.

36. Ricardo, S.B. (2004). Emergência de S. aureus Meticilina-Resistente (MRSA) na comunidade. Prática Hospitalar. 34, 131-134.

37. Santos, B.M.O.; Darini, A.L.C. (2002). Colonization by Staphylococcus aureus in healthy carriers from a nursery in a university hospital. Medicina, Ribeirão Preto. 35 (2), 160-172.

38. Siripommongcolchain, T. et al. (2002). Evolution of different primers for detecting mecA genes by PCR in comparison with phenotypic methods for discrimination of meticillin-resistant Staphylococcus aureus. Southeast Asian J. Trop. Med. Public. Health. 33 (4), 758-763.

39. Swenson, J.M.; Lonsway, D.; McAllister, S.; Thompson, A.; Jevitt, L.; Patel, J.B. (2007). Detection of mecA-mediated resistance using cefoxitin disk diffusion (DD) in a collection of Staphylococcus aureus expressing borderline oxacillin MICs. Diagn Microbiol Infect Dis. 58 (1), 33-39.

40. Tenover, F. C.; Arbeit R.; Archer, G.; Biddle, J.; Byrne, S.; Goering, R.; Hancock, G.; Hébert, G.A.; Hill, B.; Hollis, R. (1994). Comparison of traditional and molecular methods of typing isolates of Staphylococcus aureus. J. Clin. Microbiol. 32 (2), 407-415.

41. Toledo, M. R. F. (1989). Staphylococcus. In: TRABULSI, L. R. Microbiologia. 2. ed. Rio de Janeiro: Atheneu, 105-109.

42. Tomasz, A.; Drugeon, H.B.; Lencastre, H.M.; Jabes, D.; McDougal, L.; Bille. J. (1989). New mechanism for methicillin-resistance in S. aureus: clinical isolates that lack the PBP2a gene and contain normal penicilinbindig proteins with modified penicillin binding capacity. Antimicrob Agents Chemother. 33, 1869-1874.

43. Unal S, Hoskins J, Flokowitsch JE, Wu CY, Preston DA, Skatrud PL. Detection of Methicillin-Resistant Staphylococci by Using the Polymerase Chain Reaction. J.Clin.Microbiol 1992; 30(7): 1685- 1691.

44. Van Belkum, A.; Kluytmans, J.; Van Leeuwen, W.; Bax, R.; Quint, W.; Peters, E.; et al. (1995). Multicenter evaluation of arbitrarily primed PCR for typing of Staphylococcus aureus strains. J. Clin. Microbiol. 33 (6), 1537-1547.

45. Wertheim, H.; Vos, M.; Ott, A.; Van Belkum, A.; Voss, A.; Kluytmans, J.; Van Keulen, P.; Vandenbroucke-Grauls, C.; Meester, M.; Verbrugh, H. (2004). Risk and outcome of nosocomial Staphylococcus aureus bacteraemia in nasal carriers versus non-carriers. Lancet. 364 (9435), 703-705. 